\title{
PET-Saúde - Medicina e Educação em Saúde no Programa de Saúde da Família: um Relato de Caso
}

PALAVRAS-CHAVE:

- Educação em Saúde;

- Programa Saúde da Família.

- Educação Médica

KEYWORDS

- Health Education;

- Family Health Program.

- Medical Education

\section{The Educational Program for Health Work: a Case Report on Medicine and Health Education in the Family Health Program}

Adiney Ferreira Esteves Fernando Mansano Rodrigues ${ }^{I}$

Gabriela P. L. Lorecchio ${ }^{I}$

Bruna M. de Moraes Oliveira ${ }^{I}$ Maria Cristina Martinez Capel Laluna ${ }^{I}$

\section{RESUMO}

A educação em saúde no Programa de Saúde da Família é uma ferramenta para a melhoria da saúde que o profissional da está utilizando cada vez mais. Dentro desse contexto, a Faculdade de Medicina de Marília, a partir de 2003, iniciou modificações para se adaptar a esta nova demanda profissional. A partir dessas mudanças, realizou-se um relato de experiência, conforme a vivência que os estudantes teveram, registrando como foram essas modificações nos quatro primeiros anos do curso de graduação em Medicina.

\section{ABSTRACT}

Health education in the Family Health Program is increasingly used by professionals to improve healthcare. Beginning in 2009 the School of Medicine in Marília, São Paulo State, implemented changes to adapt to these new professional demands. A case report was conducted on this experience with students' reactions to changes in the first four years of their undergraduate medical training.
Recebido em: 20/09/2010

Recebido em: 20/09/2010

Aprovado em: 19/11/2010 


\section{INTRODUÇÃO}

\section{Educação em Saúde}

Saúde é um tema que há muito tempo vem sendo caracterizado de diversas maneiras. Em 1946, a OMS apresentou a seguinte definição para saúde: “O estado de completo bem-estar físico, mental e social e não somente a ausência de doença ou enfermidade $^{\prime \prime 1}$ (p. 1). Essa definição foi positiva, pois caracterizou a saúde nos aspetos físicos, sociais e psicológicos. Porém, essa ampliação do conceito de saúde para além da área médica tradicional acabou encontrando barreiras na prática, dificultando a concretização da ação e a efetiva promoção da saúde. O conceito de saúde da Constituição Federal de 1988 relaciona saúde à qualidade de vida, implicando no suprimento das necessidades sociais complexas da população nas esferas políticas, econômicas e sociais da saúde².

É nessa perspectiva do conceito ampliado de saúde que tem sido repensada a educação em saúde. Ela pode ser definida, em um primeiro momento, "como um campo de práticas que se dão no nível das relações sociais normalmente estabelecidas pelos profissionais de saúde entre si, com a instituição e, sobretudo, com o usuário, no desenvolvimento cotidiano de suas atividades"3(p. 482). Educar para a saúde "implica ir além da assistência curativa, significa dar prioridade a intervenções preventivas e promocionais" ${ }^{\prime 4}$ (p. 50)

Atualmente, existem dois modelos de educação em saúde: o tradicional e o dialógico. O primeiro enfatiza as práticas de educação que "incluem informações verticalizadas que ditam comportamentos a serem adotados para a manutenção da saúde" ${ }^{\prime 4}$ (p. 47). O segundo enfatiza a perspectiva dos sujeitos das práticas de saúde, em que o usuário é "portador de saber, que, embora diverso do saber técnico-científico, não é deslegitimado pelo serviço" ${ }^{4}$ (p. 48).

\section{Educação médica na Faculdade de Medicina de Marília}

As mudanças curriculares iniciadas em 2003 fazem parte do Projeto Famema século XXI, que visa à produção de conhecimento com base no modelo de vigilância à saúde, a partir da prática e reflexão sobre ela, buscando a transformação da aplicação profissional e da formação de profissionais de saúde, dos processos de trabalho e da qualidade de vida e de saúde das pessoas e da população. Em um currículo orientado por competência, a seleção de conteúdos, as atividades de ensino-aprendizagem, os cenários de prática e de desenvolvimento de atributos passam a estar articulados e integrados no sentido da construção do conhecimento e de outras capacidades.

A Unidade de Prática Profissional (UPP) representa o início do desenvolvimento do currículo orientado por competên- cia na nessa escola. Iniciada em 2003, ela abriu caminho para o desenvolvimento da competência, da reflexão a partir da prática e da integração das unidades educacionais.

As participações da Secretaria Municipal de Higiene e Saúde do município de Marília e Garça são fundamentais para o desenvolvimento da UPP e do currículo como um todo. Além da inserção de estudantes e docentes na rede de serviços de saúde municipal, os profissionais da secretaria também participam da elaboração e execução das unidades educacionais dos dois cursos, integrando o ensino e o trabalho em saúde.

A estrutura curricular dos cursos de graduação da Famema é organizada em duas unidades educacionais longitudinais complementares: as Unidades Sistematizadas e as Unidades de Prática Profissional, além de Unidades Educacionais Eletivas a partir da $2^{\underline{a}}$ série.

O contato com os serviços de saúde e com a comunidade, desde a $1^{\underline{a}}$ série do curso, possibilita o desenvolvimento de habilidades na análise e gerenciamento dos problemas reais de saúde, das pessoas e dos serviços, bem como de atitudes e da postura responsável e ética esperada dos futuros profissionais da área. (Relatório de Atividades da Famema 2008)

O estudante é inserido na Unidade de Saúde da Família no $1^{\circ}, 2^{\circ}$ e $4^{\circ}$ ano por meio da UPP. Na UPP1 ( $1^{\circ}$ ano) e UPP2 ( $2^{\circ}$ ano) forma-se um ciclo, que é realizado em 2 anos em uma mesma Unidade de Saúde da Família com um grupo de oito estudantes de Medicina, quatro estudantes de Enfermagem e dois tutores (sendo um médico e o outro enfermeiro). Nesse cenário, o cuidado coletivo é o mais importante.

\section{QUADRO 1}

Desenvolvimento de tarefas conforme as áreas de atuação, segundo as séries do curso de Medicina.

\begin{tabular}{|c|c|c|c|c|c|c|}
\hline & $1^{\mathrm{a}}$ & $2^{\mathrm{a}}$ & $3^{\mathrm{a}}$ & $4^{a}$ & $5^{a}$ & $6^{a}$ \\
\hline \multicolumn{7}{|c|}{ Cuidados às necessidades individuais e coletivas } \\
\hline \multicolumn{7}{|l|}{ Identifica necessidades de saúde } \\
\hline \multicolumn{7}{|l|}{$\begin{array}{l}\text { Formula o problema do } \\
\text { paciente/comunidade }\end{array}$} \\
\hline \multicolumn{7}{|l|}{$\begin{array}{l}\begin{array}{l}\text { Elabora e executa plano de } \\
\text { cuidado/intervenção }\end{array} \\
\end{array}$} \\
\hline \multicolumn{7}{|c|}{ Organização e Gestão do trabalho de Vigilância à Saúde } \\
\hline \multicolumn{7}{|l|}{$\begin{array}{l}\text { Organiza e elabora o trabalho em } \\
\text { saúde junto à equipe }\end{array}$} \\
\hline \multicolumn{7}{|l|}{$\begin{array}{l}\text { Planeja o processo de trabalho } \\
\text { junto a equipe }\end{array}$} \\
\hline \multicolumn{7}{|l|}{ Avalia o trabalho em saúde } \\
\hline \multicolumn{7}{|c|}{ Iniciação Cientifica } \\
\hline Identifica os passos da pesquisa & & & & & & \\
\hline $\begin{array}{l}\text { Formula e executa o projeto de } \\
\text { pesquisa }\end{array}$ & & & & & & \\
\hline
\end{tabular}


No $4^{\circ}$ ano, devido à UPP4, o estudante retorna 18 semanas a uma Unidade de Saúde, sendo quatro alunos por unidade (dois por período). Nessa etapa, já existe um foco individual; assim, o aluno é responsável pelo atendimento e é supervisionado pelo médico da unidade.

O aluno, no decorrer das séries, vai desenvolvendo as tarefas conforme as áreas de atuação até o final da graduação (quadro 1).

\section{RELATO DE CASO}

Partindo da concepção de que as políticas de saúde se materializam nos serviços mediante as ações de atores sociais e suas práticas cotidianas, é possível perceber o quanto se tem sido ativo no cenário da prática profissional da $1^{\mathrm{a}}, 2^{\mathrm{a}} \mathrm{e}$ $4^{\text {a }}$ séries, pois, a partir de tais ações (visitas domiciliares, grupos multidisciplinares de atuação individual e coletiva, programas de orientação a respeito de práticas de risco e práticas preventivas), os estudantes se tornam atores de sua própria educação. Por meio da UPP foi possível aos estudantes serem cada vez mais atuantes no processo saúde-doença das famílias por quem eram responsáveis, visto o bom relacionamento médico-paciente, que sempre foi imprescindível para que pudesse haver a inserção dos conceitos de educação em saúde no atendimento diário das Unidades de Saúde.

No início não se sabia o que era uma unidade de saúde, o que era unidade básica, mas com essa inserção precoce, pode-se aprender o que é ser um médico do Programa de Saúde da Família. No primeiro e segundo ano, construiu-se vínculos com famílias, realizou-se visitas domiciliares, traçou-se objetivos para o coletivo e programas de promoção com base na necessidade de saúde da população. Com isso, aprendeu-se na prática, literalmente na casa do paciente, o que era educação em saúde no SUS.

A educação em saúde no Programa de Saúde da Família fez parte dessa etapa não por apenas dar subsídios teóricos e, sim, por levar o estudante para a prática, mostrando a ele as carências da população, e o confrontando com fato de estarem ou não preparados para lidar com ela assim como ocorre no dia a dia do grupo da UPP.

A elaboração de grupos fazia parte do objetivo do estudante. Os estudantes estruturavam previamente os grupos, os quais eram discutidos com o tutor antes de entrarem em funcionamento. Os grupos eram de temáticas de interesse da população, tais como: gestação; hipertensão arterial; diabetes; entre outras. Além dos grupos, os estudantes também eram responsáveis pela capacitação dos agentes comunitários, por meio de atividades previamente organizadas.
No $4^{\circ}$ ano , esses alunos retornarão para a Unidade de Saúde da Família, porém com um enfoque no diagnóstico e tratamento de doenças. Há de se observar que a experiência que se acumulará nesses 4 anos facilitará o entendimento da importância de abordar o coletivo, realizar a promoção da saúde e capacitar as equipes para que levem saúde ao usuário.

\section{CONCLUSÃO}

Através do aprimoramento e do melhor entendimento do conceito de saúde e da melhor forma de implementá-la, de forma efetiva e igualitária, conseguiu-se, concomitantemente, aperfeiçoar o entendimento que se tinha sobre o conceito de educação em saúde. Com este relato, é possível concluir que a ciência de tal conceito por todos que atuam no cenário das Unidades de Saúde é de fundamental importância para que se possa dar ao nosso sistema um caráter preventivo, em vez de curativo. Tal concepção passa, primordialmente, por uma população bem orientada, ciente de seus deveres e direitos, com estreita relação com os atores da saúde, em que estes, por sua vez, devem ser capacitados para que possam ter subsídios para aplicar tais conceitos de forma ativa e eficiente, a partir de grupos, programas de orientação e medidas preventivas.

\section{REFERÊNCIAS}

1. World Health Organization [homepage na Internet]. Geneva: WHO; c2006 [acesso em 2006 Nov 12]. Disponível em: http:/ /www.who.int/en/

2. Papoula SR. O processo de trabalho intersetorial das Equipes de Saúde da Família no município de Petrópolis-RJ: fatores restritivos e facilitadores. Rio de Janeiro; 2006. Dissertação [Mestrado] - Fundação Oswaldo Cruz - Escola Nacional de Saúde Pública Sérgio Arouca.

3. L'Abbate S. Educação em saúde: uma nova abordagem. Cad Saúde Pública. 1994; 10(4):

4. Alves VS. Um modelo de educação em saúde para o programa saúde da família: pela integralidade da atenção e reorientação do modelo assistencial. Interface Comun Saúde Educ. 2005;9(16):39-52.

5. Agencia Nacional de Vigilancia Sanitária. [homepage]. Disponível em: http://www.anvisa.gov.br/legis/resol/2006/rdc/220_06htm.

6. Denit IA. Programa de Saúde da Família: suas possibilidades e limites na promoção da saúde e do trabalho com a família. Texto e Contexto Enfermagem. 2000;9(2): 699-713.

7. Dowbor TP. O Trabalho com Determinantes Sociais da Saúde no Programa Saúde da Família do Município de São 
Paulo. 2008. São Paulo. Tese [Doutorado] — Universidade de São Paulo

8. Ministério da Saúde. [homepage]. [acesso em 22 abr 2009]. Disponível em: http://dtr2004.saude.gov.br/susdeaz/legislacao/arquivo/PORTARIA_№_687GM.pdf.

9. Noronha MGRCS, Cardoso PS, Moraes TNP, Centa ML. Resiliência: nova perspectiva na promoção da saúde da família?. Ciênc Saúde Coletiva. 2009; 14(2):497-506.

\section{CONTRIBUIÇÃO DOS AUTORES}

Adiney F. Esteves, Fernando Mansano e Gabriela Lorec desenvolveram a pesquisa e o relato de experiência. Bruna $\mathrm{M}$ de Moraes Oliveira e Maria Cristina M. Capel Laluna orientaram todo o processo.

\section{CONFLITO DE INTERESSES}

Declarou não haver.

\section{ENDEREÇO PARA CORRESPONDÊNCIA}

Adiney Ferreira Esteves

Rua Hosuke Uchida 26, ap 206

Bairro - Marília

CEP.17519-222 SP

E-mail: af.esteves@yahoo.com.br 